\title{
Development of Epoxy Composites Containing Basalt and Carbon Fabrics and their Mechanical Behaviours
}

\section{Yusuf Şahin ${ }^{1 *}$ and De Baets Patrick ${ }^{2}$}

\author{
${ }^{1}$ Department of Mechanical Engineering, Faculty of Engineering, Near East University, Turkey \\ ${ }^{2}$ Department of Electrical Energy, Ghent University, Belgium
}

\begin{abstract}
Fiber reinforced polymer composites (FRPCS) are rapidly growing interests in market share in structural applications due to higher modulus/strength and good corrosion resistance associated with lower weight, and design flexibility. The purpose of this work is to compare hardness, three-point bending, impact and fracture properties of different reinforcement/ epoxy composites. Two types of composite fibers/fabrics were studied: Carbon woven fabric and basalt woven fabric. Therefore, basalt fabric-reinforced epoxy composites (BFRCs) and carbon fabric-reinforced composites (CFRCs) were manufactured by open molding method. The effects of the fiber weight fraction and matrix on the mechanical properties were analyzed. A comparison was performed on the mechanical properties such as hardness, flexural strength/ modulus and impact strength for BFRCs and CFRCs in accordance with ASTM standards. It was exhibited that CFRCs showed the higher hardness, higher flexural strength and modulus in comparison with BFRCs. In addition, the flexural strength/modulus increased with increasing the content of fabrics for both composites. Moreover, the fracture surface of epoxy showed a flat feature while the composite failure took place in a bridged fiber appearance after the loading flexural. In contrast to hardness, flexural strength/modulus, higher impact strengths were obtained from BFRCs than CFRCs because of the formation of the delaminated layers in the structure.
\end{abstract}

\section{Keywords}

Basalt, Carbon, Epoxy, Flexural strength and modulus, Fracture surface, Impact strength, SEM

\section{Introduction}

In recent years, basalt fibers have taken an increasing attention for possible replacement of conventional glass fibers [1] because of their advantages such as cost of environmental cost and increased physical and chemical properties.
In addition to having non-toxic, non-combustible characteristics, basalt fibers have higher chemical stability and higher tensile strength than those of E-glass fibers in compare to carbon fiber, and their failure strains are bigger [2]. Because of these favorable properties, they can be extensively useful for numbers of application fields, like chemical

* Corresponding author: Yusuf Şahin, Department of Mechanical Engineering, Faculty of Engineering, Near East University, Near East Boulvard, ZIP: 99138 Nicosia, TRNC Mersin 10, Turkey, Tel: +903922236464

Accepted: December 27, 2018; Published: December 29, 2018

Copyright: (C) 2018 Şahin Y, et al. This is an open-access article distributed under the terms of the Creative Commons Attribution License, which permits unrestricted use, distribution, and reproduction in any medium, provided the original author and source are credited.

Şahin and Patrick. Int J Metall Met Phys 2018, 3:025

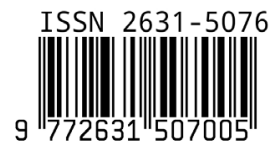


industry, automobile industry, construction, packing and high temperature-insulation applications.

Carbon fibers are commonly preferred reinforcement elements which are used in applications that require higher strength and modulus. But they have some disadvantages like lower strain to failure, poor impact resistance, and very high electrical conductivity. The applications of carbon fibers range from Sporting goods to Rocket casings in Aerospace/Aircrafts industry because of providing a more weight saving. In addition, the carbon fibers have found a potential use in the Medical industry including implant materials, and machinery such as turbines, compressors, windmill blades etc. [3]. Basalt and carbon fibers are used to obtain superior mechanical properties in the longitudinal fiber direction. In this case, why do the people use the basalt and carbon woven fabrics? Although carbon fibers indicated an excellent mechanical, chemical and physical properties, it is produced costly and have a brittle behaviour. However, two-dimensional basalt or carbon fabrics have attracted attentions due to their balanced properties and easy handling during the fabrication process of composites.

Polymer materials can be divided into three types, which are thermoplastic, thermosetting and elastomer polymer. They have got different properties because their molecular arrangement differs chemically. Thermosetting are stiffer and stronger than the thermoplastics. Thus, they can be used at high temperature applications. However, these are restricted to moulding only. Polymers will be incorporated with some reinforcements to generate a composite so that the mechanical properties of polymer improve in most practical applications. Polymer matrix composites have generated a significant amount of attention in current material research field because the structural components are manufactured with fibers/fabrics composites, and hence leading to a high strength-to-weight ratio [4]. Industry often faces some scientific problems for the composites. The lack of knowledge/understanding/mass production or new processing technique, materials, standardization/design/solution methods and recycling are the key fields, which must be developed. Thus, then the costs for the composites will be decreased, and can found many new applications. Another obstacle may be added as the lack of long durability and performance when servicing at various environment/temperature, especially for polymer composites.
In the last few years, basalt fibers have been used as reinforcements for thermoset plastics such as epoxy, polyester and vinyl ester resin to manufacture composite's structural parts. Among them, epoxy is one of the most important matrix that has found a special place for the thermoset polymers due to having its excellent mechanical properties associated with chemical and corrosion resistance [5]. Lopresto, et al. [6] investigated some mechanical property using $E$ glass and basalt fiber to evaluate the substituting the basalt fibers for the glass fibers. The experimental results exhibited that basalt revealed higher for elastic modulus, compressive, bending strength, impact force and energy, but a better tensile strength was obtained for the glass fibers [7]. Dorigato and Pegoretti [8] studied the tensile and fatigue behavior of epoxy reinforced with woven basalt, E-glass and carbon fibers. They reported that a higher performance of the laminate was obtained using basalt fabrics when compared to glass fiber composite [9-33]. Colombo, et al. [10] found a higher mechanical property against vinyl ester and indicated a more compact failure mode since fibers did not tend to explode. Wei, et al. $[11,12]$ demonstrated that the better acid resistance was obtained for the basalt reinforcements when they were treated with sodium hydroxide hydrochloric acid solutions in various times. Wei, et al. [13] found that anti-seawater corrosion properties of the both composites like basalt and glass fibers were the same approximately [14]. Carmisciano, et al. [15] indicated that a higher flexural modulus and interlaminar shear strength was obtained for the basalt fiber composites had when compared with E-glass fibers; however, a lower flexural strength was observed, while similar electrical properties were provided. Fiore, et al. [16] investigated the glass-basalt/epoxy composites for ship applications using a three point-bending tests. Tensile tests were also carried out to evaluate the impact number and position of basalt layers. The results exhibited that the existence of external layers of basalt could cause the highest escalations in mechanical properties of hybrid laminates with respect to glass fiber reinforced plastic laminates. He, et al. [17] analyzed the impact damage modes and mechanical properties of glass, aramid and basalt fiber reinforced epoxy composites. At high impact energy, basalt laminate exhibited a progressive damage with the fibers on the back-face tension fractured layer by layer, and aramid beam displayed 
a progressive evaluation [18]. The basalt polyester composites under static three-point bending loading and low-velocity impact loading were analyzed by Gideon, et al. [19], with the conclusion that unidirectional laminate indicated a superior performance with respect to woven and cross-ply in static loading, but cross-ply and woven laminate composite were superior in dynamic loading condition, respectively. In addition, vinyl ester-basalt fiber reinforced composites were used as matrix [2022]. Basalt fibers can be used with thermoplastics like polypropylene, phonelic and polyethylene. The mechanical properties including tensile and flexural strength of various polymers improved when basalt and other fibers were introduced [23]. Szabo, et al. [24] studied the static behaviour of polypropylene composites reinforced with different short fibers with varying in proportion of reinforcements $(5 \%$, $15 \%$ and $25 \%$ ), produced by compression moulding. The mechanical properties of composites were strongly influenced by fiber content and the direction of fibers. SEM of fractured surface of samples showed that the damage form was pull out in transverse and debonding in longitudinal directions [25]. Song, et al. [26] studied the mechanical properties of basalt fiber reinforced polyamide (PA) 1012 composites were prepared by melting blending method. Test results showed that the optimal tensile and flexural strength of silane treated BFRP/ PA1012 were 83.4 and $120 \mathrm{MPa}$, respectively [27]. Akinci, et al. [28] studied the mechanical and morphological behaviour of basalt filled in low density polyethylene (LDPE) with 10 to 70 wt.\% polymer composites. It was found that increased in addition of basalt filler to the LDPE resulted in a decrease in elongation at break values [29-39]. Subargia, et al. [40] studied the effect of different tourmaline micro/nano particle loading ( 0.5 to 2 wt.\%), with and without a surfactant to enhanced dispersion of the tourmaline particles on the mechanical properties of BFRP/epoxy composite laminates. The results revealed that incorporation of tourmaline particles in the BFRP/epoxy composites improved the tensile and flexural strength and modulus. Mingchao, et al. [41] studied the chemical durability and mechanical properties of unidirectional basalt fiber reinforced epoxy composites. The composites were immersed in eight kinds of chemical mediums at 15,30 , and 90 days. In alkali mediums, the flexural strength declined gradually. The tensile strength of BFRP (640 MPa) was much lower when com- pared to GFRP (1029 MPa) composites. The flexural strength of BFRP was about $716 \mathrm{MPa}$ [42]. Bulut, et al. [43] studied the mechanical properties covering tensile, flexural and impact testing of basalt fiber reinforced epoxy composite containing graphene nano-pellets (GnPs). It was found that the incorporation of GnPs fillers at $0.1 \mathrm{wt} . \%$, tensile strength was $240 \mathrm{MPa}$, flexural strength was $273.91 \mathrm{MPa}$, and impact strength was $110 \mathrm{~kJ} / \mathrm{m}^{2}$, but it was followed a decreasing trend for GnPs at 0.2 and 0.3 wt.\%, respectively.

The impact testing played an important role for optimizing the process, matrix/fiber type and interface. De Rosa, et al. [44] studied the impact performance of two woven fabric laminates including basalt/vinyl ester and E-glass/vinyl ester composites. The results indicated that maximum impact energy was $22.5 \mathrm{~J}$, degradation of specimens were not exceeding more than $15 \%$ based on the flexural strength and modulus. Moreover, much more delamination area was observed for E-glass/vinyl ester composite than that of basalt/ vinyl ester laminate composites. Manikandan, et al. [37] studied the effect of $\mathrm{NaOH}$ and $\mathrm{H}_{2} \mathrm{SO}_{4}$ on mechanical properties of BFRP/unsaturated polyester composites. The tensile strength of BFRP composites for untreated, acid treated and base treated were found to be 9.8, 24.5 and $35.45 \%$ greater than that of GFRP composites, respectively. In the impact tests, acid treated BFRP composites was $69.33 \%$ greater impact strength than GFRP composites. Botev, et al. [45] investigated the impact strength of polypropylenes (PP) filled with short basalt fibers was four times higher than that of unfilled PP. The interfacial interactions were further improved by addition of poly(propylenegmaleic anhydride). Moreover, the tensile strength for the materials was increased by $10 \%, 21 \%$ and $40 \%$, but impact strength was found to be increased by $13 \%, 24 \%$ and $29 \%$ for 5,10 and 20 wt. $\%$ of PP-gMA in the blend, respectively. Shishevan, et al. [46] compared the low velocity impact performance of BFRP/epoxy and CFRP/epoxy composites under various energy levels. Basalt fibers showed a better impact performance than CFRP. The results of the last materials showed that the change of fabrication process and curing conditions improved the impact property of BFRPs up to $13 \%$.

As a result, this study aims to develop a basalt fabric/carbon fabric epoxy composites and accord- 
ingly comparisons of some mechanical properties such as hardness, impact and three point-bending measurements on the epoxy-based composites were made in accordance with ASTM standards.

\section{Experimental Details}

\section{Materials}

Basalt and carbon fabric reinforced polymer laminates (BFRCs and CFRCs) were fabricated through compression molding method. Two different types of reinforcements employed were: Basalt dry fabrics, $200 \mathrm{~g} / \mathrm{m}^{2}$ (plain-weave), and carbon dry fabric, $180 \mathrm{~g} / \mathrm{m}^{2}$ (plain-weave), supplied from Mctechnic Inc. Thermosetting bisphenol-A epoxy (SR 8500) and amine-system harder (SD 860x) was applied as the matrix system in a ratio of 100:30. Mixture of epoxy with modified aliphatic amine hardener was supplied by the same company.

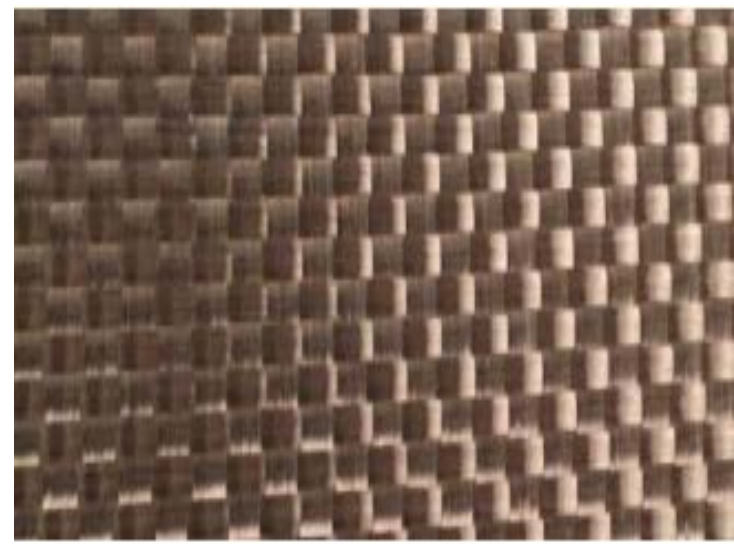

a)

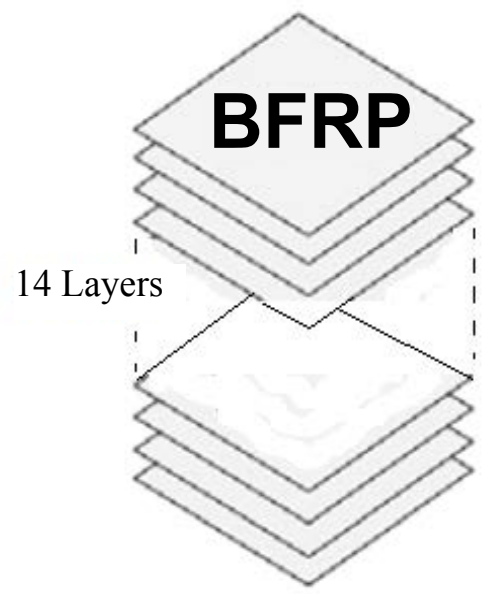

There were two kinds of basalt and carbon woven fabrics used in this study for making epoxybased composite as reinforcements. Hand lay-up and molding technic were used for the preparation of fabric reinforced thermosetting epoxy resin matrix composites. The production process consists of six steps that include: a) Mold preparation, b) Fiber/fabric preparation, c) Resin preparation, d) Resin impregnation, e) Laying-up in molding and applying the load, f) Curing of produced composite laminates. Some part of the production steps are shown in Figure 1. The characteristics and mechanical properties of basalt and carbon fabrics were given in Table 1.

The specimens $(150 \mathrm{~mm} \times 150 \mathrm{~mm} \times 4 \mathrm{~mm})$ were made from steel square laminates and then used for the mechanical characterization. A releasing agent was applied on mould to remove the laminated composite easily and to provide

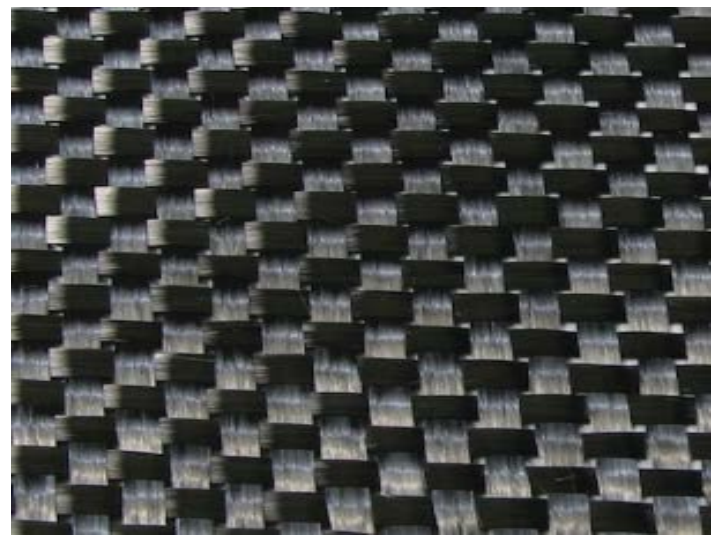

b)

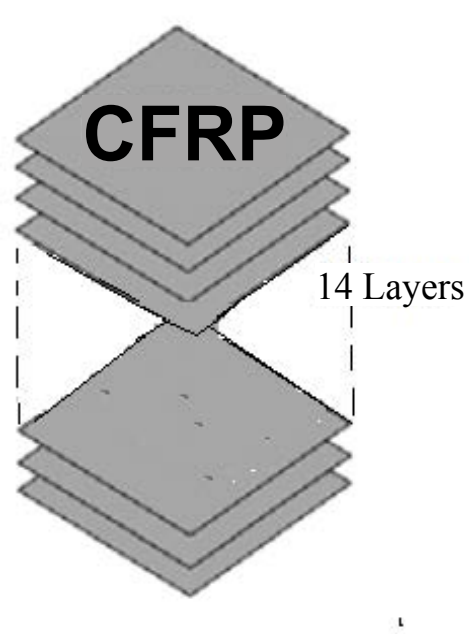

c)

Figure 1: Preparation stages of composites. a) Basalt plain fabrics; b) Carbon plain fabrics; c) Manufacturing of hand lay-up process of epoxy composites. 
Table 1: The characteristics properties of the woven basalt and carbon fabrics (Sources: Manufacturer data sheets).

\begin{tabular}{|l|l|l|}
\hline Material & $\begin{array}{l}\text { Basalt fabric } \\
\text { (BF) }\end{array}$ & $\begin{array}{l}\text { Carbon } \\
\text { fabrics }(\mathrm{CF})\end{array}$ \\
\hline & Plain & Plain \\
\hline Fabric weight $\left(\mathrm{g} / \mathrm{m}^{2}\right)$ & $220 \pm 10$ & $160 \pm 10$ \\
\hline Fabric thickness $(\mathrm{mm})$ & 0.19 & 0.25 \\
\hline $\begin{array}{l}\text { Warp construction/fill } \\
\text { construction }\end{array}$ & $22 / 26$ & $12 / 13$ \\
\hline Monofilament dimeter $(\mu \mathrm{m})$ & $10-20$ & $7-10$ \\
\hline Density $\left(\mathrm{g} / \mathrm{cm}^{3}\right)$ & 2.70 & 1.74 \\
\hline Tensile modulus $(\mathrm{GPa})$ & $80-90$ & 230 \\
\hline Tensile strength $(\mathrm{MPa})$ & $1350-4800$ & 4900 \\
\hline
\end{tabular}

more accurate surface finish. For preparing the laminate, the stacking consisted of placing the basalt fabric or carbon one above the others. For the current study, for each configuration of basalt/ epoxy composite laminate, a total of fourteen plies of basalt woven fabrics and plain carbon fibers were stacked in every laminate composite. Off course, the mixture of the resins should spread well between the fabrics. Both the bottom and the top layers of the laminates covered by the mold sheet. These were also coated with the releasing agent to make the separation easy after curing process. The assembly was pressed between plate's mould at a load of $1 \mathrm{MPa}$ for 24 hours and then allowing to cure to the ambient temperature. Finally, post curing was done at $50{ }^{\circ} \mathrm{C}$ for 24 hours. The weight fraction (wt.\%) of the both composites including basalt and carbon fibers were $0 \%, 40 \%$ and $60 \%$ for every panel of composite laminate.

\section{Microstructure}

The microstructures of the epoxy based composites including basalt and carbon fabrics were examined by Scanning Electron Microscope (SEM) of their cross-sections mounted in a transparent resin and polished up to $6 \mu \mathrm{m}$ by diamond paste.

\section{Mechanical testing}

According to the ASTM specification, different mechanical tests such as hardness, impact (ASTM D256) and flexural test (ASTM D790) were carried out using the epoxy based composites. At least five tests for each condition were performed on the whole composite samples. The hardness of the composites was measured by Rockwell B hardness method, and the mean of at least five readings was taken.

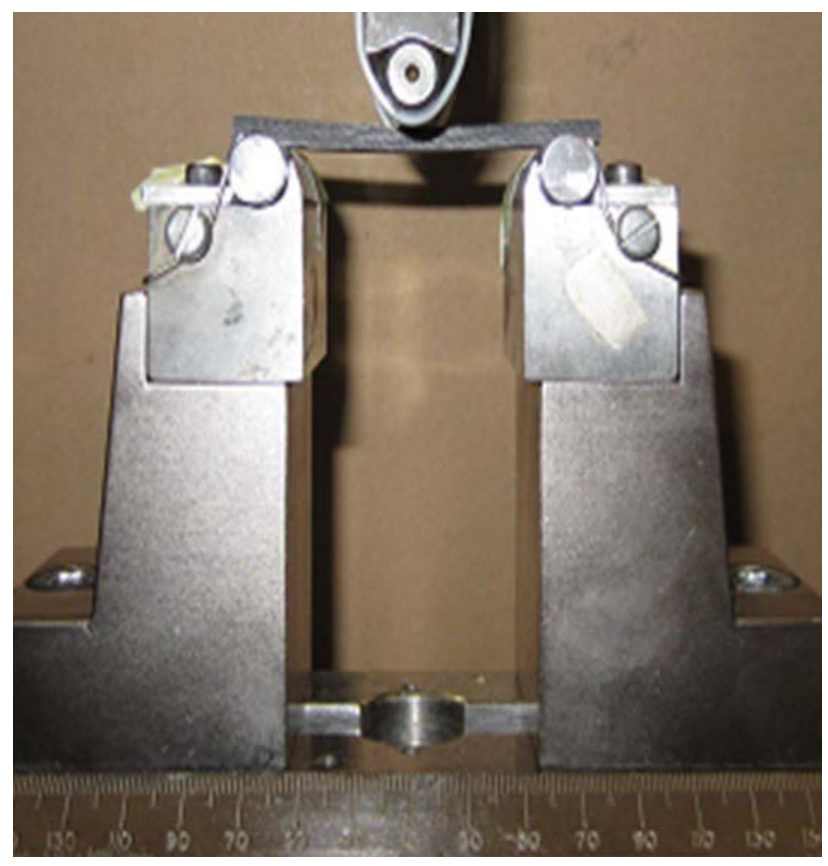

Figure 2: Three-point bending testing machine.

Flexural test: The flexural tests are the most common experiments to characterize the produced materials with three-point bending machine. The tests were carried out according to ASTM D-790 standard. A Universal Testing Machine (UTM) model 3365 by Intron was equipped with a load cell of 10 $\mathrm{kN}$. The flexural testing was particularly conducted with five prismatic samples for each composite, having the following dimensions: $64 \mathrm{~mm} \times 12.7 \mathrm{~mm}$ $\times 4.2 \mathrm{~mm}$. For all tests to be conducted, the span length depth ratio was about $16 \mathrm{~mm}$ and cross-head speed was about $2 \mathrm{~mm} / \mathrm{min}$. The mean value of the data points obtained was taken as the measured result. The load was applied at the middle of the sample until the sample was fractured, as shown in Figure 2. The fracture surfaces were examined using a photograph. During the test, the initiated load was recorded by an attached computer system.

The flexural strength can be calculated with the following equation:

$$
\sigma_{f}=\frac{3 P \times L}{2 b \times d^{2}}(M P a)
$$

Where $\sigma_{f}$ is the flexural strength (MPa), $\mathrm{P}$ is the maximum load $(\mathrm{N}), \mathrm{L}$ is the support span $(\mathrm{mm}), b$ is the measured specimen width $(\mathrm{mm})$, and $d$ is the measured specimen thickness ( $\mathrm{mm}$ ). Further, the flexural modulus may be fixed from the slope of the initial straight line part of the load-deflection curve using this equation: 


$$
E_{f}=\frac{L^{3}}{4 b \times d^{3}} \frac{\Delta P}{\Delta X}(G P a)
$$

Impact test: The impact test was performed with a standard instrument falling-weight impact analysis system with a specimen support. The impact test was used to determine the amount of energy that was required to break the specimen. In this test, an un-notched Izod Impact test was used according to ASTM D256. The specimens were kept in a cantilever position, and a pendulum has swung around the specimen. The impact energy (J) was calculated using a dial gauge that was fitted on the machine. For each test, five specimens from the composites were tested and the results were averaged. All the samples were maintained at room temperature. The surface morphology of the carbon and basalt fibers after the fracturing the specimens were characterized.

\section{Results and Discussion}

\section{Microstructures of the composites}

Figure 3 shows a SEM image of typical microstructure of a BFRC containing $40 \mathrm{wt} . \%$ of basalt fibers. This low magnification image indicates that fibers in the structure were orientated for both directions, namely parallel and cross-sectional view. This microstructure covers a few porosities in the epoxy matrix. It might be due to formation of buble or gas introduction during the production cycle. In addition, distributions of the fibers did

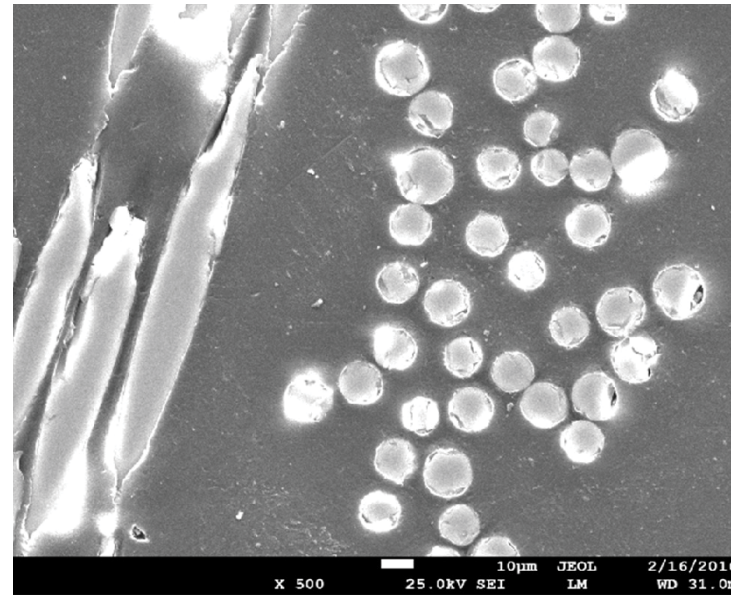

a)

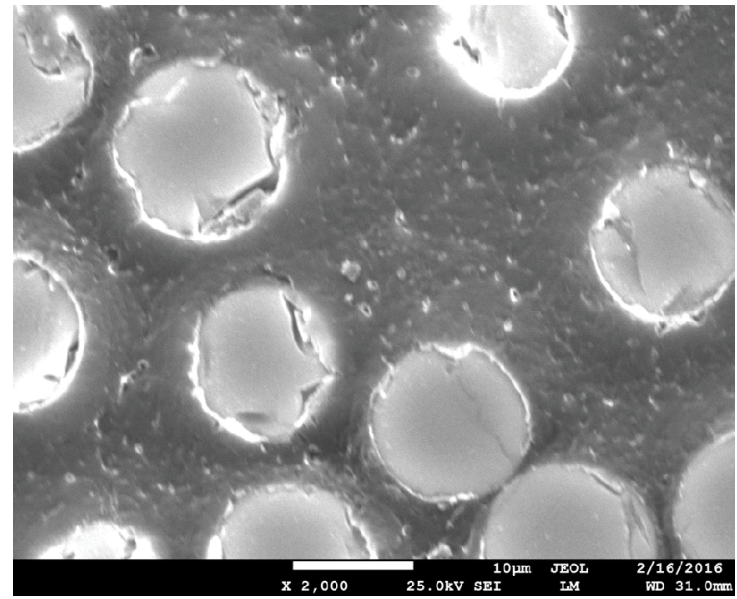

b)

Figure 3: SEM image of microstructure of a BFRC containing 40 wt.\% of fibres. a) Lower magnification; b) Higher magnification, indicating fiber fractures from ends in the epoxy resin.

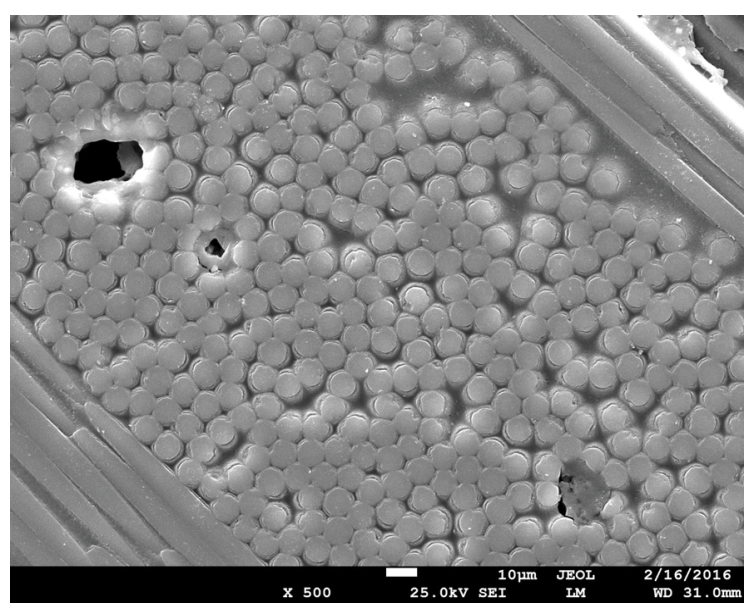

a)

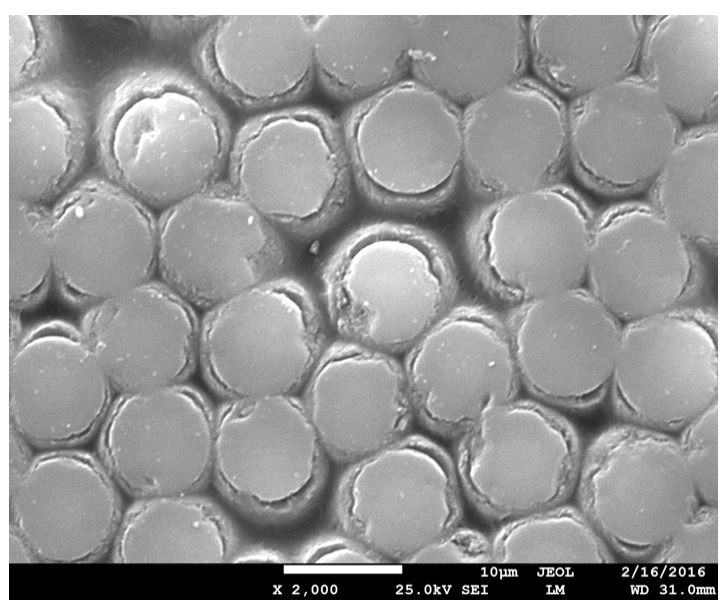

b)

Figure 4: SEM image of microstructure of a CFRC containing 60 wt.\% of fibres. a) Lower magnification; b) Higher magnification, exhibiting more uniform fiber distributions in the structure. 
not seem to be uniform because lower contents of the fibers were used. It was exhibited in Figure $3 \mathrm{~b}$ that some fiber's fractures from the ends or surface were observed under higher magnification for the most of the fiber's cross-section because of an achievement of enough bonding between the fabrics and the matrix. Figure 4 exhibits a SEM image of typical microstructure of a CFRC containing 60 wt.\% of carbon fibers. This micrograph shows that fibers were orientated in both fiber direction and normal section. A few porosities can be observed in the resin. Figure $4 b$ reveals the microsture of the carbon epoxy composite under high magnification. This SEM image indicated more uniform distributions of fibers in the structure. Moreover, a few fibers fracturing from the ends was observed, but some debondings were also evidenced. This might be some fibers were fractured or having got some defects during mechanical processing stage because fibers/particles have very sensitive against the mechanical contacts or defected areas over the reinforcement surface. These micrographs showed that the distribution of fibers and interface bonding/interactions between the fibers and matrix was found to be the most significant factor affecting on the mechanical properties for both tested epoxy composites.

\section{Density and hardness results}

Density and hardness of both types of epoxy composites are indicated in Table 2, Figure 5a and Figure 5b. Average sintered density of EP, 40 wt.\% BF, 60 wt.\% BF reinforced composites were 1.123, 1.598 and $1.908 \mathrm{~g} \times \mathrm{cm}^{3}$, respectively. However, the density decreased considerably for carbon fabric reinforced composites such as $40 \mathrm{wt} . \% \mathrm{CF}$ and $60 \mathrm{wt} . \%$ CF laminates were about 1.41 and $1.464 \mathrm{~g}^{\circ} \mathrm{cm}^{-3}$, respectively. The theoretical density was also calculated. The maximum error was found for BF60 reinforced composites, but it was very low for CF60 laminates, which showed that the interface bonding was much better for carbon fabric composites. The hardness

Table 2: Average maximum force to break composites, standard deviation, its flexural strength and flexural modulus (the data quoted are all average results taken from a minimum of five tests).

\begin{tabular}{|l|l|l|l|l|l|l|l|l|}
\hline $\begin{array}{l}\text { Tested } \\
\text { materials }\end{array}$ & Code & $\begin{array}{l}\text { Max } \\
\text { force (N) }\end{array}$ & $\begin{array}{l}\text { Stand. dev. } \\
\text { for force } \\
\text { (\%) }\end{array}$ & $\begin{array}{l}\text { Flexural } \\
\text { strength } \\
\text { (MPa) }\end{array}$ & $\begin{array}{l}\text { Flexural } \\
\text { modulus } \\
\text { (GPa) }\end{array}$ & $\begin{array}{l}\text { Wt., \% } \\
\text { (\%) }\end{array}$ & $\begin{array}{l}\text { Rock.B } \\
\text { hardness } \\
\text { (HRB) }\end{array}$ & $\begin{array}{l}\text { Impact } \\
\text { energy (J) }\end{array}$ \\
\hline Epoxy & EP & 352 & 56 & 83 & 3.43 & 0 & 41 & 2.4 \\
\hline 40 wt.\% BF & BF40 & 739 & 36.81 & 315 & 16.78 & 40 & 48 & 15 \\
\hline 60 wt.\% BF & BF60 & 990 & 87.58 & 359 & 18.36 & 60 & 60.3 & 16.8 \\
\hline 40 wt.\% CF & CF40 & 1254 & 100.14 & 601.9 & 38.68 & 40 & 84 & 8.6 \\
\hline 60 wt.\% CF & CF60 & 1474 & 92.08 & 700 & 41.68 & 60 & 91 & 13 \\
\hline
\end{tabular}

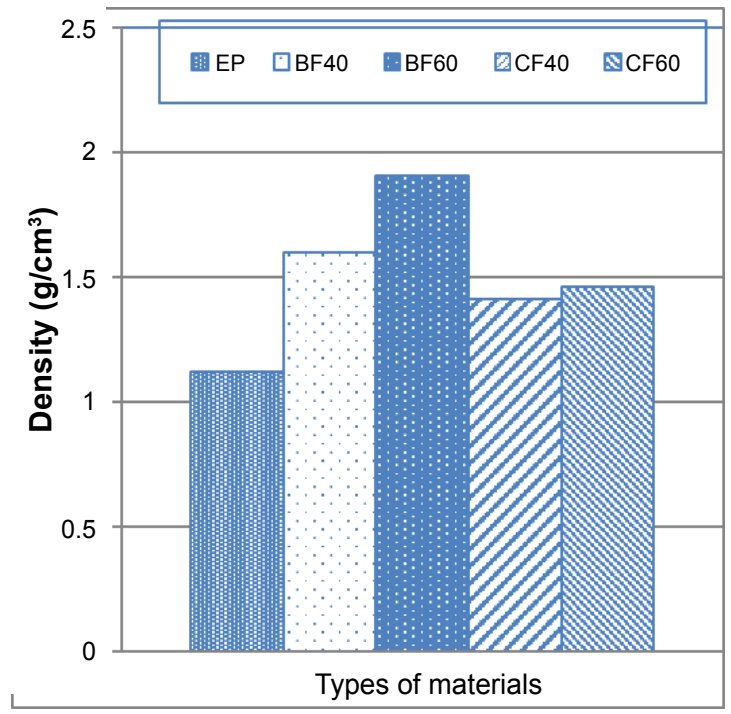

a)

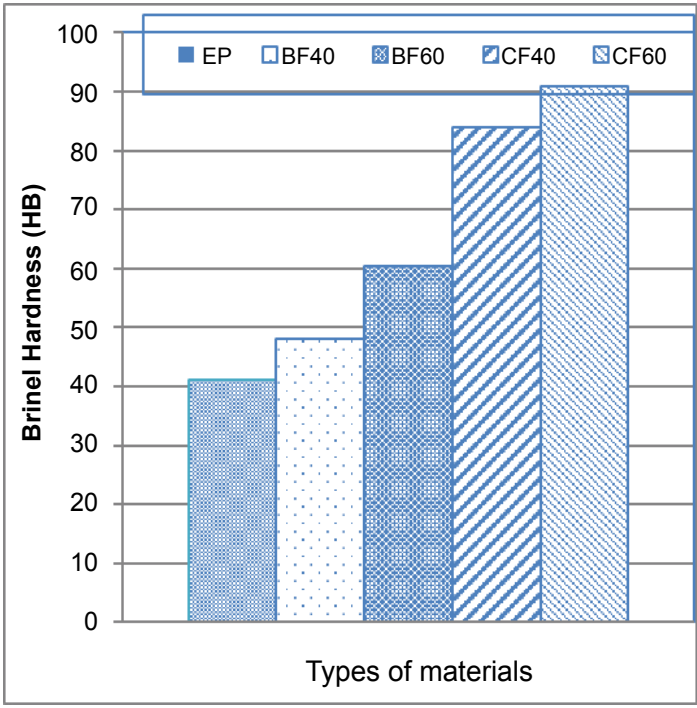

b)

Figure 5: a) The density of the laminate composite; b) Hardness of the laminate composite. 
increased from $41 \mathrm{HRB}, 48 \mathrm{HRB}$ to $60.3 \mathrm{HRB}$ for EP matrix, 40 wt.-\% BF and 60 wt.\% BF-reinforced epoxy composites, respectively (Figure $5 b$ ). The improvements in BFs for 40 wt.\% and 60 wt.\% in comparison with EP matrix were about $17 \%, 47 \%$ respectively. However, the hardness increased more significantly with increasing the carbon contents. The improvements in CF40 and CF60 composites were more or

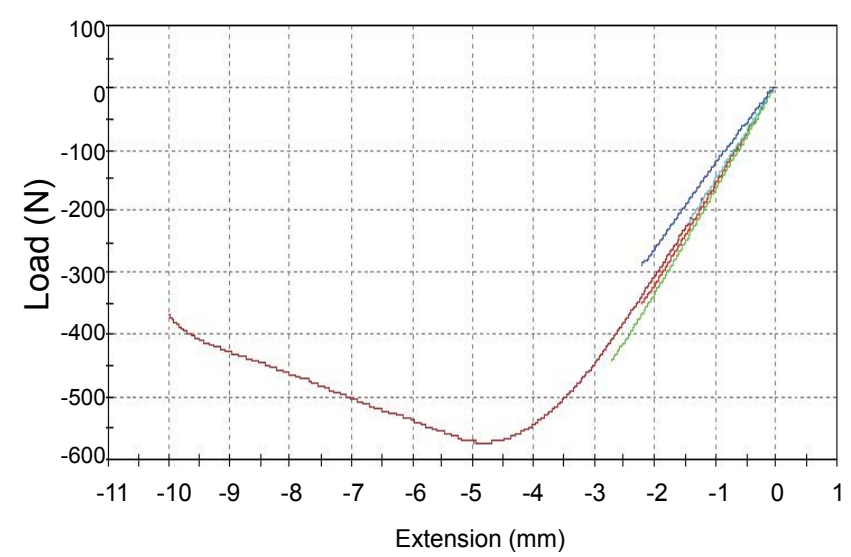

a) EP

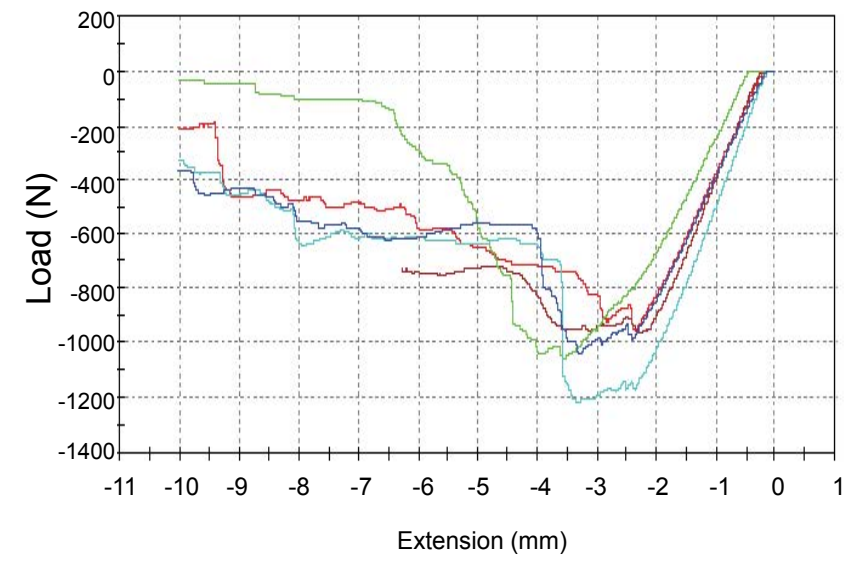

c) BF60 less $105 \%, 122 \%$, respectively. The strengthening of EP was achieved by forming an enough interface bonding between the matrix and fibers, especially for the carbon reinforced composites.

\section{Load vs. extension behaviour}

Typical load versus extension tests for flexural strengths was shown in Figure 6a, Figure 6b, Figure

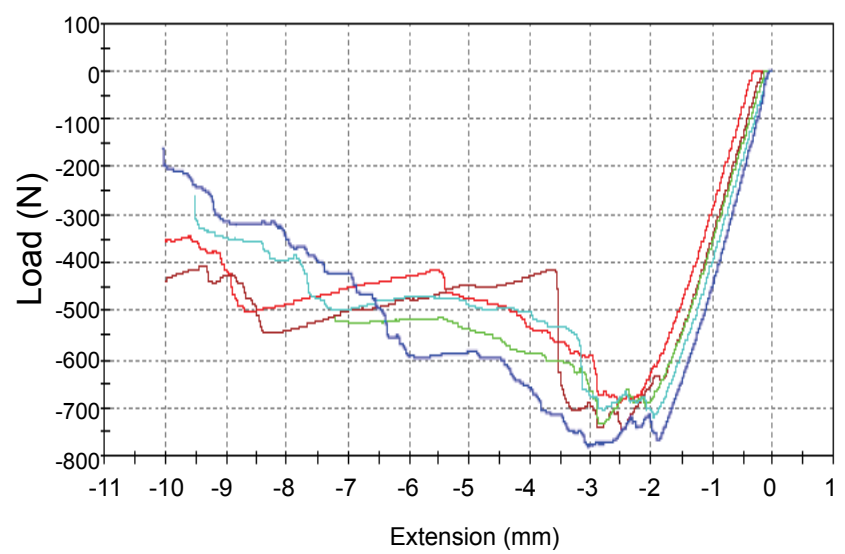

b) BF40

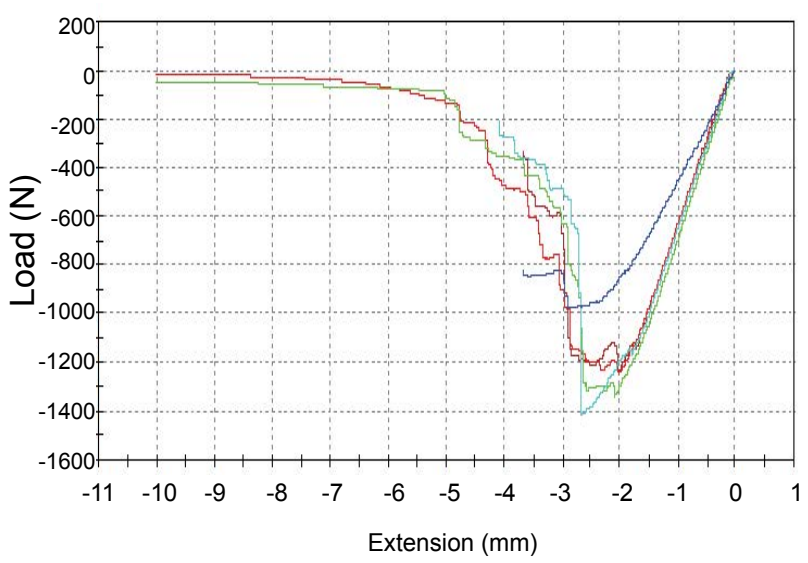

d) $\mathrm{CF} 40$

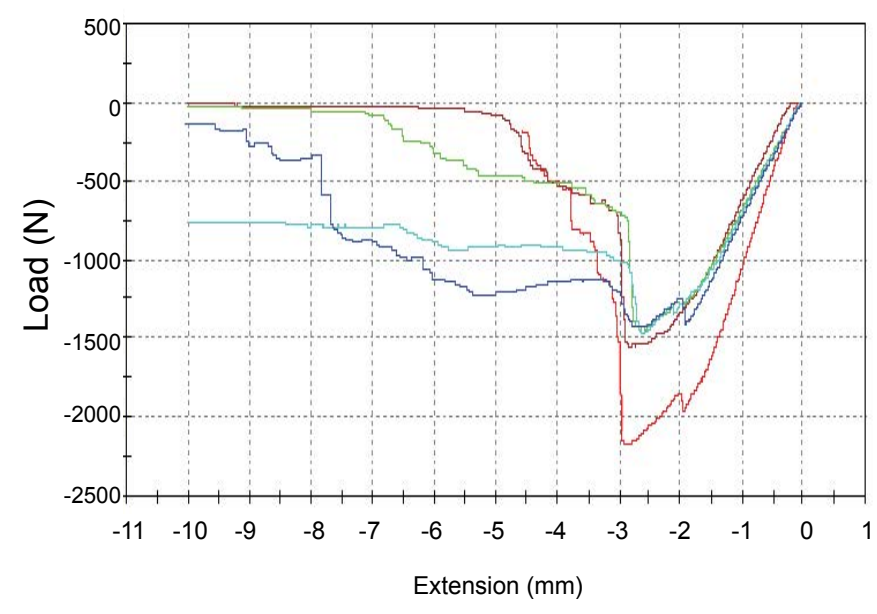

e) CF60

Figure 6: Typical loads and extension curves for BFRCs and CFRCs. a) EP matrix; b) BF40 fabric; c) BF60-fabric; d) CF40-fabric; e) CF60-fabric. 
$6 c$, Figure $6 \mathrm{~d}$ and Table 2 for EP matrix, its BF and CF reinforced epoxy composites. The flexural strength was obtained by taking the maximum load as the failure load for all the specimens. These figures indicated a linear behavior before the load reached its maximum level, followed by a gradual drop to a low value in the flexural strength. The flexural strength of EP was found to be about 83 $\mathrm{MPa}$, which was shown in Table 2. The flexural strength increased with incorporation of both fabric types used. However, the maximum flexural strength was achieved for 60 wt.\% CF composites. Similar trends were observed for BF reinforced composites. The ultimate flexural strain of BF40 composite was more than CF40 composite (Table 2). In brief, the improvement of fabric dispersibility and achievement of a good interfacial bonding between the epoxy and carbon fabrics, CFRCs led to a better flexural strength and modulus than those of BFRCs (Figure 3 and Figure 4).

\section{Flexural strength}

Figure $7 \mathrm{a}$ and Figure $7 \mathrm{~b}$ show the experimental results of the flexural strength/elastic modulus of the epoxy composites, respectively. It was obvious that the flexural strength of carbon fabrics had significantly higher values than that of the basalt fabrics and the pure epoxy resin. The presence of the carbon fabrics in the EP matrix more effectively enhanced the tensile strength from $83 \mathrm{MPa}$ to 700 $\mathrm{MPa}$ and the strength increased by about $743 \%$ due to the higher strength of the carbon fibers and an achievement of quite enough interface bonding between the fibers and the epoxy resin. However, the strength of EP increased by $332 \%$ for BF60 reinforced composite. This result indicated both flexural and modulus properties of the composites made with 28 layers were slightly larger than 14 layers composites, but the differences were not significantly high. The improvement in strength of BF40 reinforced composite was about $14 \%$ when compared to $60 \mathrm{BF}$ reinforced composites. However, it was contrary to the previous study carried out by Katsiropoulos, et al. [34]. The trends in the young modulus were similar to the flexural strength of the composites. Combining the results in Figure $7 a$ and Figure $7 b$, it was clear that the flexural/modulus of the EP resin increased gradually with the incorporation of both fabrics for different weight fractions. As the fabric-filled epoxy composite subjected to loading, the fabrics acted as carriers the applied load and stress transferred from the matrix along the fibers, resulted in good mechanical properties or requiring higher forces to break the composite specimens, as shown in Table 2. The carbon fabric having higher modulus of elasticity resulted in more improvements in stiffness for the final laminate composites. The young modulus and strengths of carbon/epoxy composites were also improved by the addition of carbon nanotubes (CNTs), but the flexural properties of the composites were improved by applying silane process or adding reinforcements $[24,27,28,35,40,41]$. Especially, the silane-treated CNT composites indicated about 34\% and 20\% larger flexural modulus and strengths than acidtreated epoxy composites, respectively. Another result indicated that the flexural modulus of

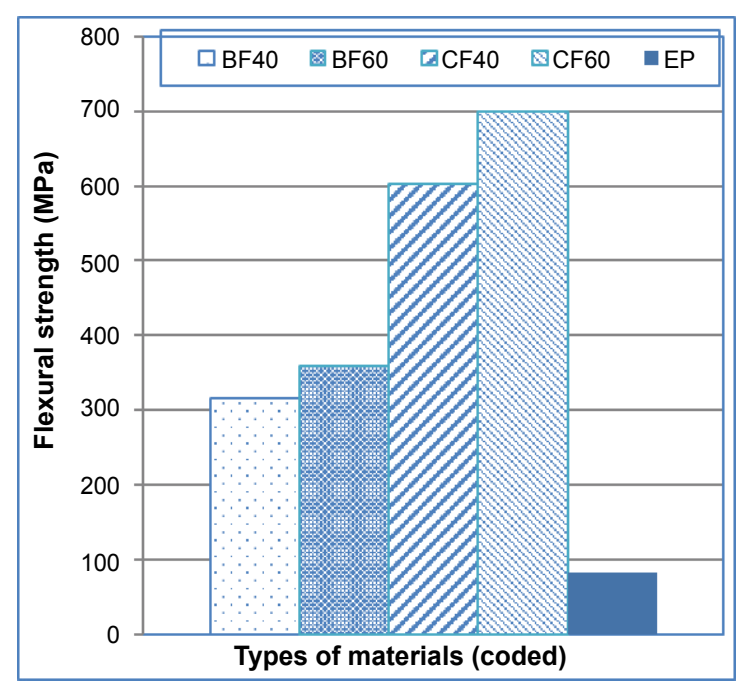

a)

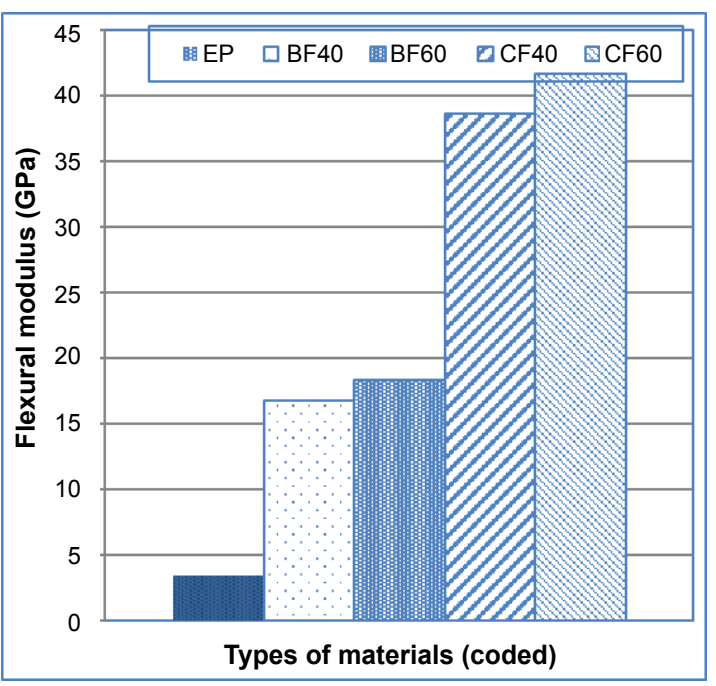

b)

Figure 7: a) The flexural strength of laminate composites; b) The flexural modulus of laminate composites. 


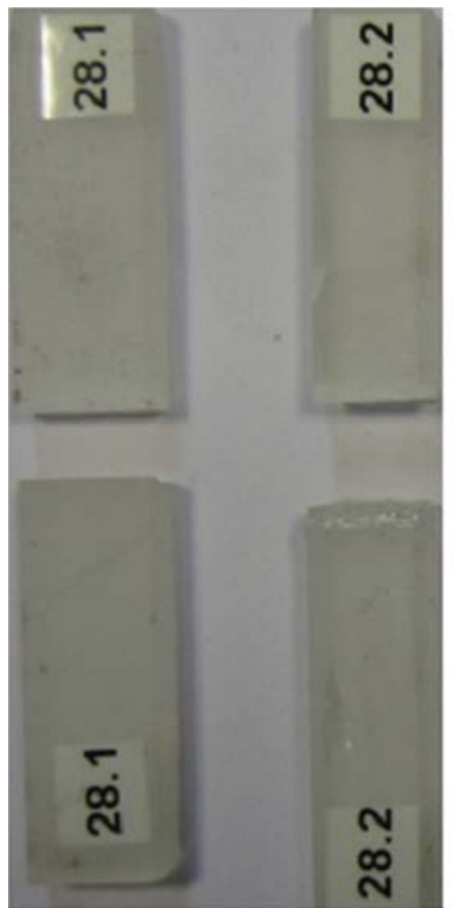

(a)

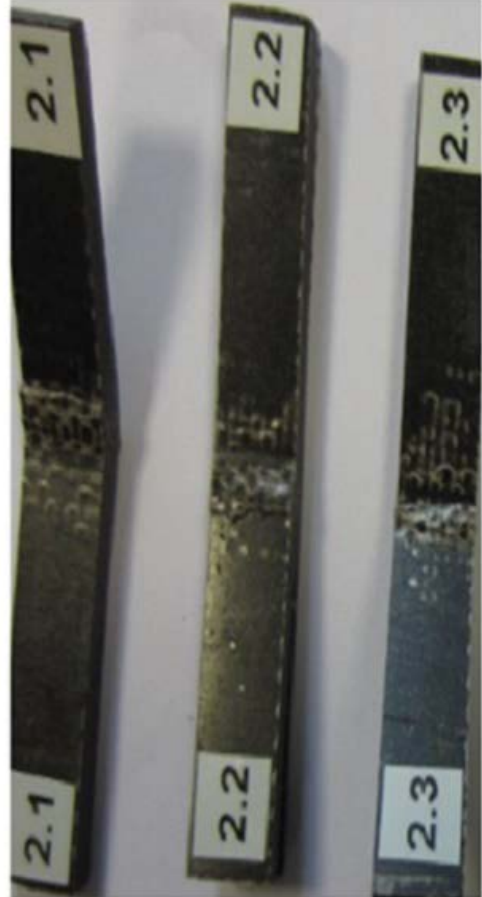

(b)

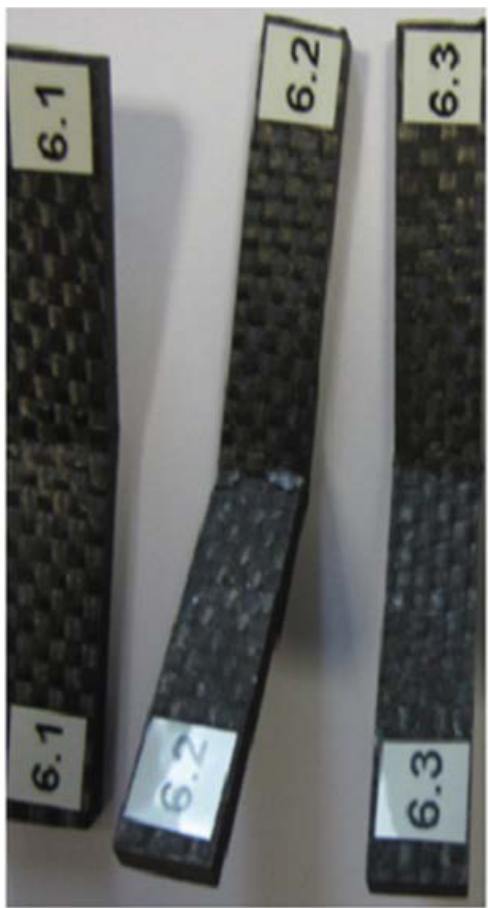

(c)

Figure 8: Photographs showing side and front views of failure surfaces loaded in flexural testing of the epoxy composites. a) EP matrix; b) BF40 reinforced composite; c) CF40 reinforced epoxy composites.

the B1-6 structures equaled to $19.5 \mathrm{GPa}$, which was more or less $118 \%$ higher than that of GFRC laminate [15].

\section{Fracture surface}

The common failure modes under flexural loadings cover compressive failure, tensile failure, shear and/or delamination, wherein failure by compression is the most common type [34]. Figure 6 indicates the photographs of the failure surfaces of EP, and its BF/epoxy and CF/epoxy composites, respectively. It could be seen in Figure 8 a that EP showed a brittle behavior because the matrix failed in flat feature, but Figure $8 \mathrm{~b}$ shows quite a different failure behavior. Epoxy resin has high modulus and good dimensional stability. However, these highly crosslinked networks are inherently brittle and consequently have limited utility requiring high fracture strength. Some specimens from epoxy composites did not indicate a fully break up laminate into two halves, which might be due to the bridging effect of the basalt and carbon fabric layers and fabric configurations [19]. A whitening region was observed for BF reinforced composite while fracturing the fabrics. This might be coming from the debonding or delamination [35]. BF reinforced composite failed in a rumpled fiber appearance after flexuring load, but there was a some difference for CF reinforced composite, as shown in Figure 8c, respectively. The buckling stress effectively transferred along the carbon fibers so that the higher flexural strength was obtained for this type of composite because of the more brittle property. It can be seen that some cracks occurred along the center line of buckling load, which were resulted in the lower elongation and higher strength. In carbon fibre/epoxy system, shear failure can also occur in compression, with the transition from buckling to shear depending on matrix shear modulus and fibre shear strength. Figure 9 shows the application of flexural force against epoxy resin, basalt and carbon fabric reinforced composites. This figure indicated that crack initiation, delamination layers and failure of smooth surface were responsible evidence for EP, BFRC and CFRC, respectively.

\section{Impact strength}

The impact resistance of the epoxy composite is to measure the total energy dissipated in the material before final failure occurs. The impact strengths of the epoxy composites including carbon and basalt fabrics was given in Table 2 and Figure 10. It was shown that the impact strength was made from different contents of the basalt and carbon fabrics including numbers of plies in the epoxy resin. The first evidence from this figure indicated that 


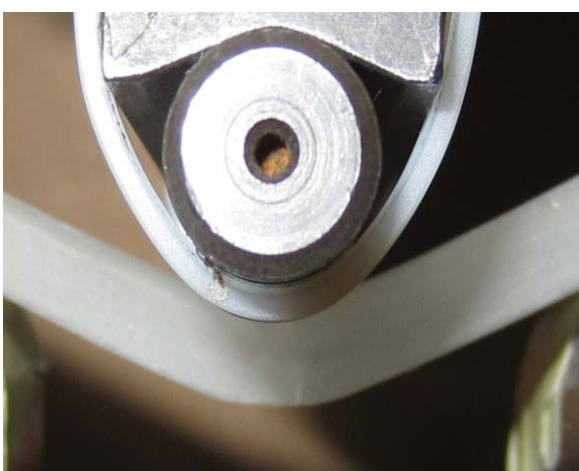

a)

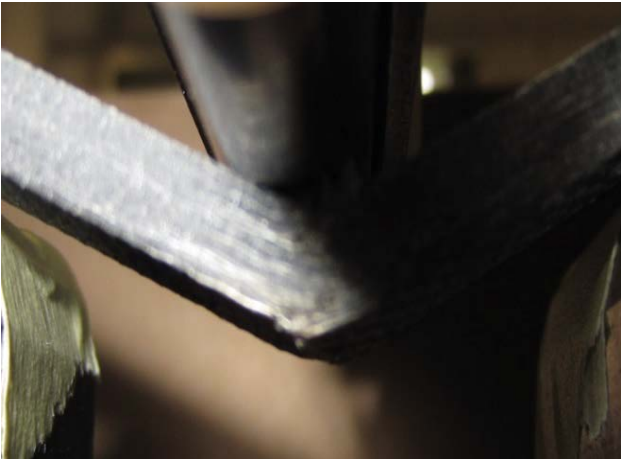

b)

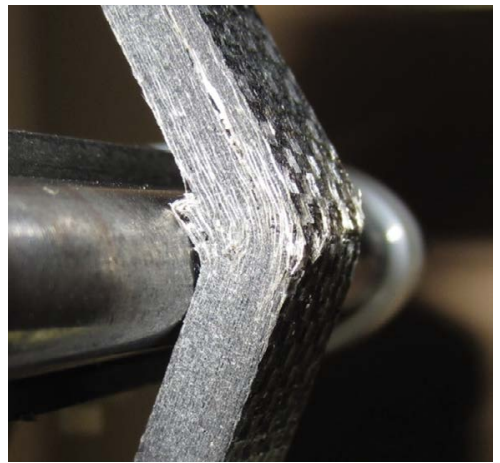

c)

Figure 9: Application of flexural force on epoxy and 60 wt.\% fabric reinforced composites. a) Epoxy resin, exhibiting an initiation of cracks from the outer surface; b) BFRC, showing smooth surface, but not clear delamination; c) CFRC using the flexural testing, indicating fiber failure and delamination of layers.

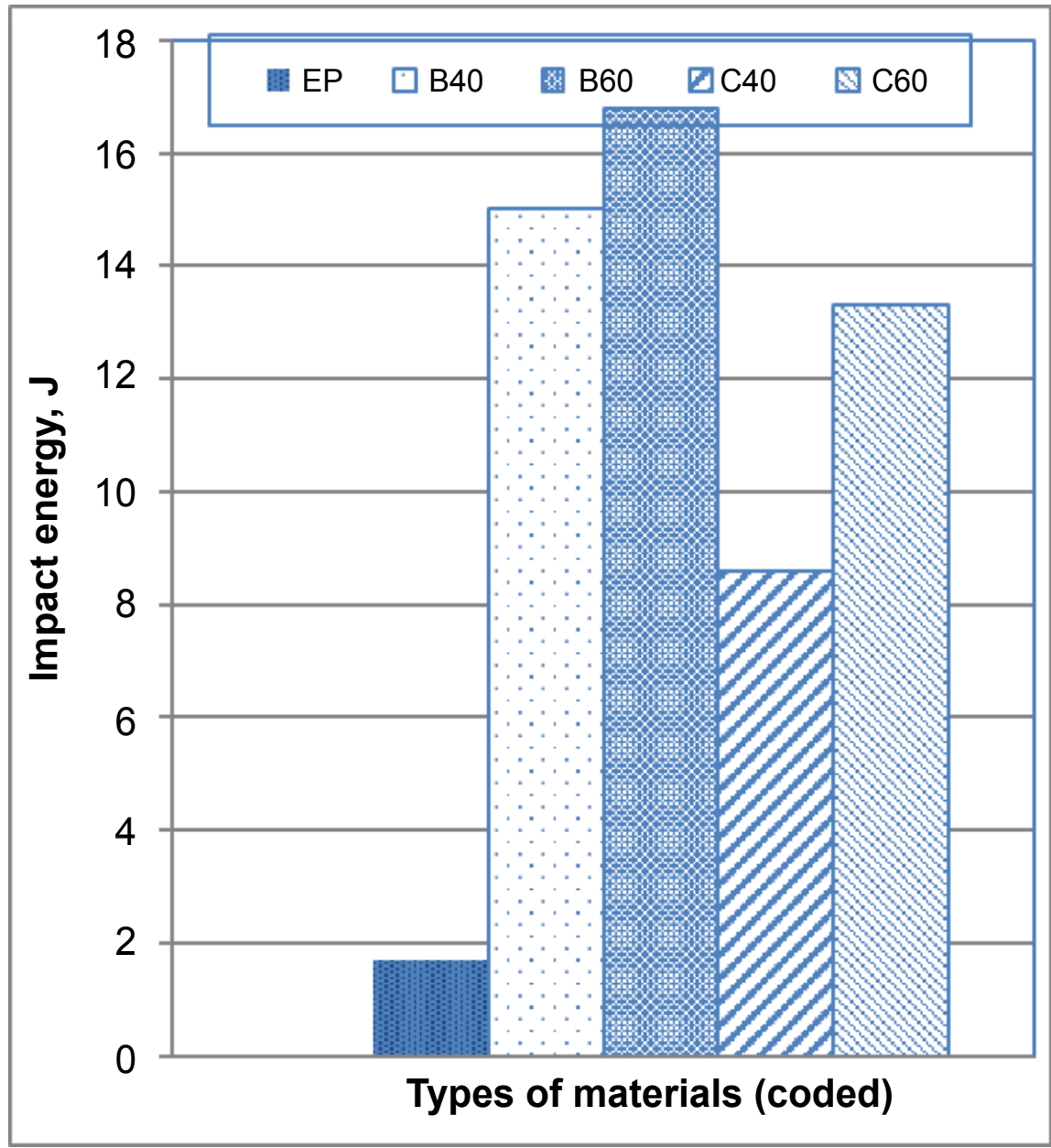

Figure 10: The impact energy of the tested epoxy and its composites.

higher impact strength was obtained from the basalt fabrics than the carbon fabrics because of the formation of the delaminated layers in the structure. The second clear result was evident: higher weight fraction of the composites gave better impact properties for both types of the composites. In other words, 60 wt.\% fabrics composite exhib- ited higher impact strength than 40 wt.\% of fabric reinforced composite. In general, the impact strength of the epoxy was primarily determined by the impact strength of the matrix, while the impact strengths of BFRC or CFRC were basically determined by the impact strengths of the basalts or/ and carbon fibers. The impact strengths of BFRCs 
were found to be larger due to the role of the numbers of the plies and large numbers of BF reinforced epoxy interface, so there were higher possibilities of debondings and delamination's, which were less obvious for CF reinforced composites. In contrast to the hardness, the flexural strength/modulus and the impact strengths measured were around 15.9 and 10.8 for BFRCs and CFRCs, respectively. The improvement in BF composites was about $47 \%$ in terms of impact energy. Figure $11 \mathrm{a}$ and Figure $11 \mathrm{~b}$ shows the photographs of the fracture surfaces of BF40 and BF60 reinforced composite, respectively. It was observed that fiber pulling-out, fiber debonding/delaminating was dominated on the fracture surface of BF reinforced composites. This confirmed that there exists a poor interface bonding between the fibers and the resin, which was not the case for CF reinforced composites, and this indicated higher mechanical properties (Table 2). Moreover, Figure 11 shows the photographs of side and front views of the representative failures loaded in impact testing of the epoxy composites.
Figure $11 \mathrm{c}$ and Figure $11 \mathrm{~d}$ indicates the failure surfaces of CF40 and CF60 reinforced composites, respectively. This surface covered the brittle failure fracture, where the samples were broken through all the layers with abundant amount of carbon fibers ruptures, which confirmed the better interfacial bonding, but the other types of the composites revealed more combinations of matrix and fiber fractures, exhibiting the poor bonding between the fibers and the epoxy, and thus leading to lowering mechanical properties. The basalt fibre reinforced laminate was found to be tougher than the glass fiber reinforced composite [36]. The impact behaviour of the acid-treated basalt fibre reinforced composite were greater than the acid-treated glass fibre reinforced composite. The deformation and energy absorption properties of geopolymeric concrete were improved considerably when adding the basalt fibre, but not significant improvement was achieved for dynamic compressive strength. Increasing matrix strength led to decreasing the deformation capacity and increase of energy ab-

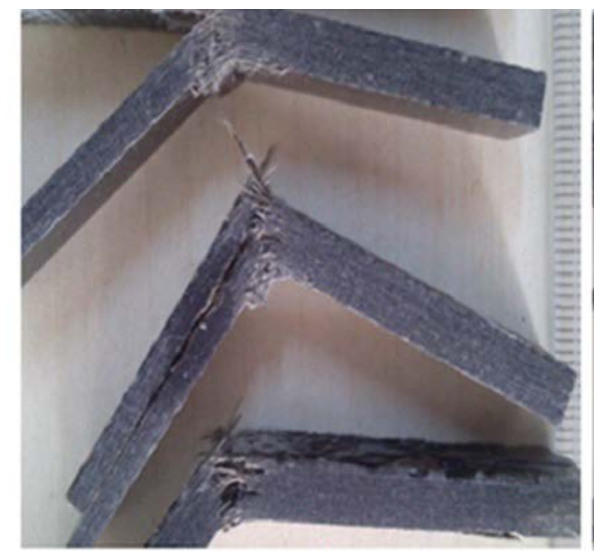

(a)

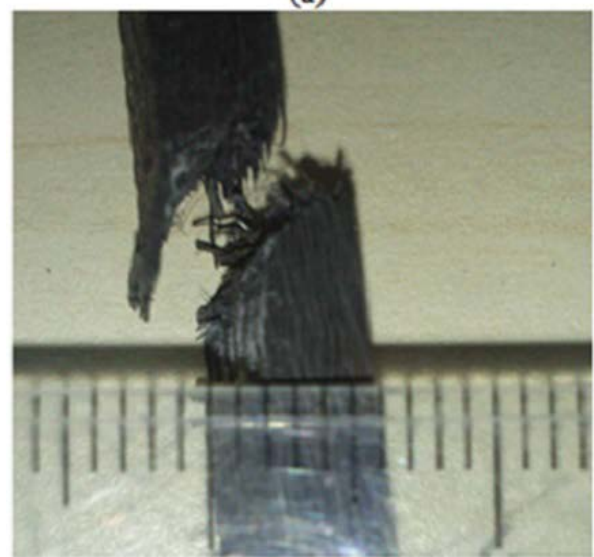

(c)

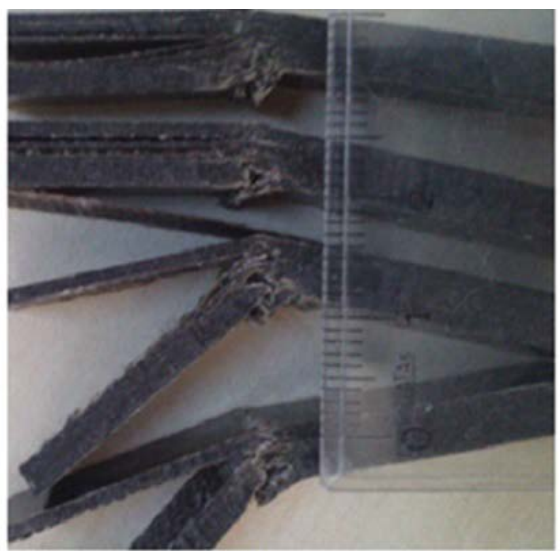

(b)

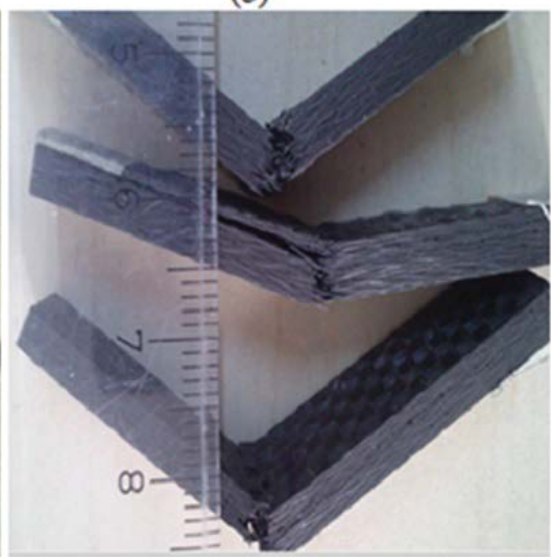

(d)

Figure 11: Photographs exhibiting side and front views of representative failures loaded in impact testing of the epoxy composites. a) BF40 reinforced composites; b) BF60 reinforced composites; c) CF40 reinforced composites; d) CF60 reinforced composites. 
sorption capacity for basalt fibre reinforced geopolymeric concrete $[37,38]$. Basalt fibers indicated higher toughness performance than CFRPs [46], which is a good agreement with the present study.

\section{Conclusions}

The following conclusions were drawn from the current study on basalt and carbon reinforced epoxy composites including different weight fraction of fibers.

- Basalt fabric-reinforced epoxy composites (BFRCs) and carbon fabric-reinforced composites (CFRCS) were manufactured by hand lay-up and compression molding method. Mechanical properties such as hardness, flexural and impact strength were investigated in accordance with ASTM standards and a comparison is made for both composites.

- The experimental results indicated that hardness of the composites changed with type of fabrics and increased with increasing wt.\% for both fibers/fabrics. The incorporation of the carbon fabrics in the resin more effectively enhanced the flexural strength from $83 \mathrm{MPa}$ to $700 \mathrm{MPa}$ and the strength increased by about $743 \%$ due to an achievement of quite enough interface bonding between the fibers and the epoxy resin. However, the strength of the epoxy increased by $332 \%$ for BF60 reinforced composite. In contrast to this, impact strength was better for BFRCs than CFRCs.

- Furthermore, fracture surface of the resin indicated a flat feature, but BF/CF-reinforced composite failed in/bridged fiber appearance after the flexural loading. Incorporation of basalt fibers into the epoxy resin exhibited a significant improvement, which was about $47 \%$ when compared to carbon fibers in the impact strength because of higher possibilities of delamination's and debondings.

\section{Acknowledgements}

This study has financially supported by "The Scientific and Technical Research Council of Turkey (TUBITAK) (Grant No. 1059B191401938) and by Soete Laboratory (Ghent University, Belgium) (own resources).

\section{References}

1. Deak T, Czigány T (2009) Chemical composition and mechanical properties of basalt and glass fibers: A comparison. Text Res Journal 79: 645-651.

2. Routray S, Biswal KC, Barik MR (2015) Effect of fiber orientation on the mechanical properties of fabricated plate using basalt fiber. Res J Recent Sci 4: 202-208.

3. Toubal L, Karama M, Bernard L (2005) Stress Concentration in a circular hole in composite plate. Comp Struct 68: 31-36.

4. Lopresto V, Leone C, De Iorio I (2011) Mechanical characterization of basalt fiber reinforced plastic. Compos Part B: Eng 42: 717-723.

5. Wei B, Song Sh, Cao H (2011) Strengthening of basalt fibers with nano-SiO-epoxy composite coating. Mater Des 32: 4180-4186.

6. Dorigato A, Pegaretti A (2012) Fatigue resistance of basalt fibers-reinforced laminates. J Compos Mater 26: 773-780.

7. Liu Q, Shaw MT, Parnas RS, McDonnel AM (2006) Investigation of basalt fiber composite aging behavior for applications in transportation. Polym Compos 27: 475-483.

8. Colombo C, Vergani L, Burman M (2012) Static and fatigue characterization of new basalt fiber reinforced composites. Compos Struct 94: 1165-1174.

9. Wei B, Cao H, Song S (2010) Environmental resistance and mechanical performance of basalt and glass fibers. Mater Sci Eng A 527: 4708-4715.

10. Wei B, Cao H, Song S (2010) Tensile behavior contrast of basalt and glass fibers after chemical treatment. Mater Des 31: 4244-4250.

11. Wei B, Cao H, Song SH (2011) Degradation of basalt fiber and glass fibre/epoxy resin composites in seawater. Corros Sci 53: 426-431.

12. Shokrieh MM, Memar M (2010) Stress corrosion cracking of basalt/epoxy composites under bending loading. Appl Compos Mater 17: 121-135.

13. Carmisciano S, Igor MDR, Sarasini F, Tamburrano A, Valente M (2011) Basalt woven fiber reinforced vinyl ester composites: Flexural and electrical properties. Mater Des 32: 337-342.

14. Fiore V, Di Bella G, Valenza A (2011) Glass-basalt/ epoxy hybrid composites for marine applications. Mater Des 32: 2091-2099.

15. He C, Li Y, Zhang Z, Sun Z (2008) Impact damage modes and residual flexural properties of composites beam. J Reinf Plast Compos 27: 11631175. 
16. Sfarra S, Ibarra-Castanedo $C$, Santulli $C$, Paoletti A, Paoletti D, et al. (2013) Falling weight impacted glass and basalt fiber woven composites inspected using non-destructive techniques. Compos Part B: Eng 45: 601-608.

17. Gideon RK, Hu H, Wambua P, Gu B (2014) Characterizations of basalt unsaturated polyester laminates under static three-point bending and low-velocity impact loadings. Polym Compos 35: 2203-2213.

18. Zhang Y, Yu C, Chu PK, Lv F, Zhang C, et al. (2012) Mechanical and thermal properties of basalt fiber reinforced poly(butylene succinate) composites. J Mater Chem Phys 133: 845-849.

19. Černý M, Glogar P, Sucharda Z (2009) Mechanical properties of basalt fiber reinforced composites prepared by partial pyrolysis of a polymer precursor. J Compo Mater 43: 1109-1120.

20. De Rosa IM, Marra F, Pulci G, Santulli C, Sarasini F, et al. (2012) Post-impact mechanical characterization of E-glass/basalt woven fabric interply hybrid laminates. J Appl Compos Mater 19: 475-479.

21. Yusriah L, Mariatti M, Bakar AA (2010) The properties of vinyl ester composites reinforced with different types of woven fabric and hollow phenolic microspheres. J Reinf Plast Compos 29: 3066-3073.

22. Cerný M, Glogar P, Golis V, Hruska J, Jakes P, et al. (2007) Comparison of mechanical properties and structural changes of continuous basalt and glass fibers at elevated temperatures. Ceram Silik 51: 8288.

23. Ozturk S (2005) The effect of fibre content on the mechanical properties of hemp and basalt fiber reinforced phenol formaldehyde composites. J Mater Sci 40: 4585-4592.

24. Szabo JS, Czig any T (2003) Static fracture and failure behavior of aligned discontinuous mineral fiber reinforced polypropylene composites. Polym Test 22: 711-719.

25. Farsani RE, Khalili SMR, Hedayatnasab Z, Soleimani $N$ (2014) Influence of thermal conditions on the tensile properties of basalt fiber reinforced polypropylene-clay nanocomposites. Mater Des 53: 540-549.

26. Bashtannik PI, Kabak Al, Yakovchuk YY (2003) The effect of adhesion interaction on the mechanical properties of thermoplastic basalt plastics. Mech Compos Mater 39: 85-88.

27. Song J, Liu J, Zhang $H$, Chen L, Zhong $Y$, et al.
(2015) Basalt fiber-reinforced PA1012 composites: Morphology, mechanical properties, crystallization behaviors, structure and water contact angle. J Compos Mater 49: 415-424.

28. Akinci A (2009) Mechanical and morphological properties of basalt filled polymer matrix composites. J Mater Sci Eng 35: 29-32.

29. Hoto R, Andres J, Cabillic B, García JA (2011) Optimization of mechanical properties of basalt woven/APA- 6 composite parts by means of velocity control. ICCM 18.

30. Song J, Liu J, Zhang H, Yang W, Chen L, et al. (2014) PVDF/PMMA/Basalt fiber composites: Morphology, melting and crystallization, structure, mechanical properties, and heat resistance. J Appl Polym Sci 131: 404-494.

31. Chairman CA, Subramani P (2013) Mechanical and abrasive wear behavior of glass and basalt fabricreinforced epoxy composites. J Appl Polym Sci 130: 120-130.

32. Carlsson LA, Pipes RB (1997) Lamina compressive response: Experimental characterization of advanced composite materials. $\left(2^{\text {nd }}\right.$ edn), Lancaster, Technomic Publishing, USA.

33. Katsiropoulos ChV, Pantelakis SpG, Meyer BC (2009) Mechanical behavior of non-crimp fabric PEEK/C thermoplastic composites. Theor Appl Frac Mech 52: 122-128.

34. Kim MT, Rhee KY, Lee JH, Hui D, Lau AKT (2011) Property enhancement of a carbon fiber/epoxy composite by using carbon nanotubes. Compos Part B 42: 1257-1261.

35. Dong CS, Ranaweera JHA, Davies IJ (2012) Flexural properties of hybrid composites reinforced by S-2 glass and T700S carbon fibers. Compos Part B 43: 573-581.

36. Li Y, Xian XJ, Choy CL, Guo M, Zhang Z (1999) Compressive and flexural behaviour of ultra-high modulus polyethylene fiber and carbon fiber hybrid composites. Compos Sci Technol 59: 13-18.

37. Manikandan V, Winowlin Jappes JT, Suresh Kumar SM, Amuthakkannan P (2012) Investigation of the effect of surface modifications on the mechanical properties of basalt fibre reinforced polymer composites. Compos Part B 43: 812-818.

38. Petr $G$, Zbynik $S$, Martin È, Stephan $P$, Herwig $P$ (2007) Microstructure and mechanical properties of heat resistant composites reinforced with basalt fibres. Ceram. Silik 51: 190-197. 
39. Weimin L, Jinyu X (2009) Impact characterization of basalt fiber reinforced geopolymeric concrete using a 100-mm-diameter split Hopkinson pressure bar. Mater Sci Eng A 513-514: 145-153.

40. Subagia Ary, Leonard D Tijing, Yonjig Kim, Cheol Sang Kim, Felipe P Vista IV (2014) Mechanical performance of multiscale basalt fiber-epoxy laminates containing tourmaline micro/nano particles. Composites Part B: Eng 58: 611-617.

41. Mingchao Wang, Zhang Zuoguang, Li Yubin, Li Min, Sun Zhijie (2008) Chemical durability and mechanical properties of alkali-proof basalt fiber and its reinforced epoxy composites. J Reinf Plast Comp 27: 393-407.

42. Scalici T, Pitarresi G, Badagliacco D, Fiore V, Valenza A (2016) Mechanical properties of basalt fiber reinforced composites manufactured with different vacuum assisted impregnation techniques. Com- posites Part B: Eng 104: 35-43.

43. Bulut, Mehmet (2017) Mechanical characterization of Basalt/epoxy composite laminates containing graphene nanopellets. Composites Part B: Eng 122: 71-78.

44. De Rosa IM, Marra F, Pulci G, Santulli C, Sarasini F, et al. (2011) Post-impact mechanical characterisation of glass and basalt woven fabric laminates. Appl Comp Mater 19: 475-490.

45. Botev M, Betchev H, Bikiaris D, Panayiotou C (1999) Mechanical properties and viscoelastic behavior of basalt fiber-reinforced polypropylene. J Appl Poly Sci 74: 523-531.

46. Shishevan, Farzin Azimpour, Hamid Akbulut, MohtadiBonab MA (2017) Low velocity impact behavior of basalt fiber-reinforced polymer composites. J Mater Eng Perform 26: 2890-2900. 